Research Article

\title{
Research on the Effect of English Talents Gathering Based on Big Data Hotspot Collection Technology
}

\author{
Chunyan Wei (iD \\ Xuchang University, Xuchang 461000, China \\ Correspondence should be addressed to Chunyan Wei; 12012047@xcu.edu.cn
}

Received 14 April 2021; Revised 6 May 2021; Accepted 10 May 2021; Published 24 May 2021

Academic Editor: Shah Nazir

Copyright (c) 2021 Chunyan Wei. This is an open access article distributed under the Creative Commons Attribution License, which permits unrestricted use, distribution, and reproduction in any medium, provided the original work is properly cited.

\begin{abstract}
Talent is the best group in human resources, and the Talents are the best group in human resources, and English-speaking talents are the most dynamic factor in productivity. In order to improve the quantitative analysis ability of the English talent aggregation effect, the English talents aggregation effect analysis model is proposed based on large-scale data collection technology. The collection information flow model of the hotspot big data of English talents aggregation effect is constructed. The high-dimensional feature grouping method is used to reconstruct the hotspot big data of the English talents aggregation effect. The piecewise linear test method is used to analyze the statistical characteristics of the hotspot big data of the English talents aggregation effect and extract the frequent vector set which reflects the hot big data category attribute of the English talents aggregation effect. According to the result of feature extraction, the fuzzy English talents aggregation is processed to realize the fusion of big data information of English talents aggregation effect hotspot. Combined with quantitative analysis method, the automatic classification of big data association rules is realized. The experimental and simulation results show that the proposed method is more accurate and effective than the traditional methods in collecting hotspot data, which is $26 \%$ and $76 \%$ higher than the traditional methods. This method has better accuracy and improved data aggregation effect in collecting hotspot data of English talents gathering and has strong collecting ability and characteristics. The research improved hotspot big data's English talents gathering effect.
\end{abstract}

\section{Introduction}

A large number of scientific and technological talents are introduced and trained under the guidance of the development and cultivation of strategic emerging industries and the emphasis on the growth needs of enterprises [1]. By introducing the team as a whole, the core talents led by the introduction, the development of high and new technology projects, the introduction of postdoctoral workstations, etc., it is necessary to introduce talents from overseas study abroad who are in urgent need of the development of industries, as well as famous domestic experts, and cultivate a group of academic leaders, forming a group of outstanding scientific and technological talent groups and teams. Talent is the best group in human resources. English talent is the most dynamic factor in productive forces, and the flow of English talents among regions can form a phenomenon of English talents gathering in a certain region [2]. It can improve the level of scientific research and education of English talents and reduce the transaction cost. Its main characteristics are spatial, clustering, and scale. The phenomenon of English talents aggregation can produce two kinds of effects: one is the economic effect of English talents gathering, and the other is the diseconomic effect of English talents aggregation. The economic effect of English talents aggregation refers to the aggregate effect of English talents gathering in a certain region in accordance with certain internal relations and under the action of harmonious internal and external environment [3].

The main reasons for the formation of diseconomic effect are that the accumulation of English talents does not form the internal relationship between English talents, the environment of English talents gathering is not ideal, the mobility is not strong enough, and all kinds of conflicts occur in the organization. In order to study conveniently, this paper classifies the diseconomic effect of English talents 
aggregation as the phenomenon of English talents aggregation, and it classifies the economic effect as English talents gathering effect. The overall characteristics of English talents aggregation can be divided into organizational effect, environmental effect and self-effect of English talents aggregation [4]. The specific characteristics can be divided into eight characteristics: information sharing effect, knowledge spillover effect, innovation effect, collective learning effect, incentive effect, time effect, regional effect, and scale effect. The following are the contributions of the proposed study.

(i) In order to improve the ability of quantitative analysis of English talents aggregation effect, a model of English talents aggregation effect analysis based on big data hotspot collection technology is proposed.

(ii) The collection information flow model of the hotspot big data of English talents aggregation effect is constructed, and the grouping reconstruction of the hotspot big data of English talents aggregation effect is carried out by using the high-dimensional characteristic grouping method.

(iii) By using the piecewise linear test method, the statistical characteristics of the hotspot big data of English talents aggregation effect are analyzed, and the frequent vector sets reflecting the hot big data category attributes of the English talents aggregation effect are extracted.

(iv) According to the result of feature extraction, the fuzzy English talents aggregation is processed to realize the fusion of big data information of English talents aggregation effect hotspot. Combined with the method of quantitative regression analysis, the automatic classification of hotspot big data association rules of English talents aggregation effect is realized.

(v) Finally, the performance test is carried out by the simulation experiment, and the validity conclusion is obtained.

\section{Analysis on the Aggregation Effect of English Talents and the Countermeasures of Talent Attract}

English talents receive long years of education and have a higher level. Whether they can give full play to their talents often depends on the cultural background of science and education in the region where the English talents are located. Good regional science and education culture can make English talents have a stage in this environment, show their "fantastic ideas," stimulate their creative inspiration, and produce the knowledge spillover effect and innovation effect of talent gathering. In the English talents aggregation effect, the talent aggregation mode is mainly reflected in the following aspects:

(1) Strengthen the flow of talents and open the channel of tacit knowledge sharing. On the one hand, it is necessary to break the existing administrative authority of personnel unit ownership and departmental ownership, to change "unit person" into "social person," so that talent can flow freely throughout the country and promote the formation of talent gathering phenomenon. After the gathering of talents, the opportunities of knowledge sharing and information exchange of English talents increase. Through information exchange, more and more knowledge and experience can be obtained, thus forming a more reasonable knowledge structure. Reasonable knowledge structure is the basis of forming innovation ability, without solid knowledge accumulation, and it is difficult to form rich association and creative thinking. On the other hand, to establish innovative learning organizations, English talents can be influenced and cultivated in a specific learning environment by participating in activities, reflection, conversation, communication, cooperation, problem solving, and so on. For example, through academic debates, symposia, expert consultations, and so on, these forms can promote the exchange and sharing of tacit knowledge to a certain extent, so that participants can share time and space. All expressions such as expressions, words, actions, and eyes, all sensory organs are receiving information. At the same time, communication is stimulated and guided by timely stimulation and feedback. Many tacit knowledge which is difficult to communicate can be met in this kind of communication, and tacit knowledge is exchanged and shared in these activities. Compared with explicit knowledge, tacit knowledge has a logical primacy, is the guide of mastering clear knowledge, is the internal motive force of human's cognitive behavior and ultimately determines the creative performance of human beings.

(2) Optimizing the creative environment of talents and transforming government functions. To create a good social atmosphere of introducing, emphasizing, knowing, loving, cultivating, and using talent, to create favorable conditions for promoting the strategy of strengthening the country by talents, and to optimize the environment of innovation and entrepreneurship of talents to ensure that people use their talents to the best of their ability. First, it is necessary to build a career platform for talent innovation and entrepreneurship. Persist in using industry to gather talents, attract talents with projects, retain talents with career, make talents have the opportunity to start a business, have stage for officers, and have room for development. Second, we should pay close attention to and protect talented people, actively guide all kinds of talents to establish a correct world outlook, outlook on life, values, consciously strengthen moral cultivation, further carry forward the spirit of dedication and hard work, unity and cooperation, honesty and trustworthiness, 
constantly improve themselves in practice, improve themselves in competition, and enrich yourself in your struggle. Third, relax the field of English talents venture capital. All kinds of English talents are allowed to invest in entrepreneurship in all fields not restricted by the state in various forms, English talents in enterprises and institutions are encouraged to stay without pay, leading the establishment of economic entities and striving to improve the investment and financing environment for English talents to innovate and start businesses. Fourth, it is necessary to change the functions of the government, to build a service-oriented government, to provide services for the gathering of talents, and to enable talented people to work happily in a harmonious environment, thus stimulate their enthusiasm for knowledge innovation.

(3) Improve the ability of both spillovers and recipients through training. The knowledge spillover subject and the recipient subject directly determine the quality of knowledge dissemination and acceptance, and the quality of knowledge dissemination and acceptance directly determines whether knowledge can produce all kinds of innovative performance. Organizations can organize various kinds of training, make English talents enrich knowledge, perfect knowledge structure, improve the quality of knowledge dissemination and acceptance, and promote the production of innovation effect [5-7].

\section{Hotspot Big Data Collection and Feature Parameter Extraction of English Talents Gathering Effect}

The hot big data information flow of English talents aggregation effect is constructed, and the high-dimensional characteristic grouping method is used to reconstruct the hotspot big data of English talents aggregation effect. $x_{n-i}$ represents the fuzzy distribution of the hotspot big data attribute set of the English talents aggregation effect and $\eta_{n-j}$ is expressed as the association rule distribution set of the big data attribute characteristic vector of the English talents aggregation effect hotspot, and then the English talents gather [8]. The information flow model of the set effect hotspot big data attribute set is expressed as follows:

$$
x_{n}=a_{0}+\sum_{i=1}^{M_{A R}} a_{i} x_{n-i}+\sum_{j=0}^{M_{M A}} b_{j} \eta_{n-j}
$$

where $a_{0}$ is the sampling amplitude of the big data time series of the initial English talents gathering effect and $b_{j}$ is the statistical characteristic of hotspot big data of English talents aggregation effect which is analyzed by using piecewise linear test method. $x(t)$ is the optimal association rule distribution attribute of hotspot big data of English talents aggregation effect, $t=0,1, \ldots, n-1$. For the scalar time series of hotspot big data of English talents aggregation effect, the finite set of big data set distribution of English talents aggregation effect hotspot is obtained by using the method of piecewise test:

$$
\frac{1}{2 \pi m} \sum_{k=-q / 2}^{q / 2} b_{k} \sum_{i=0}^{p} a_{i}\left(n+c_{k} m\right)^{i}=\frac{1}{2 \pi} \sum_{i=0}^{p} a_{i} n^{i-1} .
$$

According to the result of vector reconstruction, the feature extraction of association rules of big data, a hotspot of English talents aggregation effect, is carried out [9].

\section{Big Data Classification of English Talents Aggregation Effect}

4.1. Feature Extraction of Association Rules. On the basis of constructing the data information flow model of English talents aggregation effect, using the high dimension feature grouping method to reconstruct the hot data of the English talents aggregation effect, this paper carries out the automatic classification and optimization design of the hot data of the English talents aggregation effect. This paper puts forward the social people based on the association rules [10]. According to the autocorrelation matching constraints, the detection statistics of the hot data classification of the English talents aggregation effect are expressed as follows:

$$
\begin{aligned}
\min F(x) & =\left(f_{1}(x), f_{2}(x), \ldots, f_{m}(x)\right)^{T}, \\
\text { s.t. } & g_{i} \leq 0, \quad i=1,2, \ldots, q, \\
& h_{j}=0, \quad j=1,2, \ldots, p,
\end{aligned}
$$

where $T$ is the time variable of the hotspot of English talents gathering effect. In the solution space of association rule distribution, the optimal English talents gathering center search is carried out, and the judgment function of the hot big data category judgment of English talents aggregation effect is obtained as follows:

$$
\text { Thre }=\max _{b}\left|\int r(t) \frac{1}{\sqrt{a^{\prime}}} f^{*}\left(\frac{t-b}{a^{\prime}}\right) d t\right|=\max _{b}\left|W_{f} r\left(a^{\prime}, b\right)\right| \stackrel{H_{1}>}{<_{H_{0}}} \lambda_{2}
$$

where $\lambda_{2}$ is the second decision threshold, and the initial feature vector $x(t)$ of the hotspot big data output of English talents aggregation effect includes the association rule vector, and the feature extraction method of association rule is adopted [11]. The results of big data feature extraction of English talents aggregation effect are expressed as follows:

$$
C(l)=\sum_{j=1}^{k} \sum_{k=1}^{n_{j}}\left(\left\|x_{k}^{j}-A_{j}(L)\right\|\right)^{2} .
$$

Under the influence of disturbance error, the English talents gathering center is satisfied with the disturbance error $\|C(l)-C(l-1)\|<\xi$, and the iterative formula of English talents gathering center in finite vector set is calculated in the disturbed range. The English talents 
aggregation is the hotspot of English talents gathering effect big data. The iterative formula of English talents gathering is

$$
A_{j}(L+1)=1 / n_{j} \sum_{i=1}^{k} X_{i}^{j} \quad j=1,2, \ldots, k .
$$

According to the above feature extraction results, combined with the fuzzy English talents aggregation algorithm, the big data automatic classification design of the hotspot of English talents aggregation effect is carried out [12].

\subsection{Characteristics of English Talents Gathering Effect Auto-} matic English Talents Gathering. On the basis of extracting the association rule vector set which reflects the hot big data category attribute of English talents aggregation effect, the fuzzy English talents aggregation processing is carried out according to the feature extraction result [13]. By using the grouping attribute correlation information of the hotspot big data of English talents aggregation effect, the measurement information of the hotspot big data of English talents aggregation effect is judged, and the classification measures are obtained as follows:

$$
E=\sum_{p=1}^{n} E_{p}=\frac{1}{l} \sum_{p=1}^{n} \sum_{k=1}^{l}\left[r_{p}(k)-y_{p}(k)\right]^{2} .
$$

In the rule vector set, the English talents gathering center with the hot big data characteristics of English talents aggregation effect is expressed as

$$
u=\sum_{j=0}^{n} a_{j} \tanh ^{j} \xi
$$

Euler distance is used to represent the collection center of the two groups of English talents aggregation vectors in the hotspot big data classification of English talents aggregation effect [14], which are expressed as follows:

$$
\Delta E=-\eta\left[\left(\frac{\partial E}{\partial \omega}\right)^{2}+\left(\frac{\partial E}{\partial b}\right)^{2}\right]
$$

and

$$
f(x)=\left\{\begin{array}{l}
f(x), x \in \operatorname{Lev} f \\
a, x \in \text { Levf }
\end{array}\right.
$$

It can be seen that the convergence function of the error function of the hotspot big data classification of English talents gathering effect is

$$
\left|f\left(x_{0}+h\right)-P_{n}(h)\right| \leq A|h|^{a} .
$$

By using the fuzzy C-means method of English talents aggregation, the hotspot big data information fusion of
English talents aggregation effect is carried out, the hotspot big data classification of English talents aggregation effect is realized, and the big data hotspot ability of English talents gathering effect is improved [15].

\section{Simulation Experiment}

In order to test the application performance of this algorithm in big data collection and clustering analysis, simulation experiments are carried out. The data processing algorithm is designed with MATLAB. The scale of big data sampling is 1024, the scale of training sample set is 200 , the time period of hotspot data collection is $0.25 \mathrm{~ms}$, the simulation time is $100 \mathrm{~s}$, and the English talents aggregation effect is hot. The initial sampling frequency of the point big data $f_{s}=40 \mathrm{KHz}$, in different sampling periods, the test set of different hotspots of English talents gathering effect big data is obtained, and the result of big data hotspot collection is shown in Figure 1.

Taking the big data hotspot of English talents gathering collected in Figure 1 as the research object, the feature analysis of English talents gathering is carried out, and the result of feature extraction is shown in Figure 2.

Figure 2 shows that this method can accurately collect the big data hotspots of English talents, and the clustering of feature extraction is good. The accuracy of big data hotspot collection with different methods is tested, and the results are shown in Figure 3. Figure 3 shows that the three methods are compared with the accuracy of big data's hotspot collection and English talents collection, and the aiming time is $10: 00$. The recall rate of the method in this paper is 933. The recall rate of the proposed method in reference [5] is 67 . The recall rate of the method in this paper is 26 times higher than that in reference [5]. The recall rate of the proposed method in reference [7] is 76. The method in this paper is more effective than that in [7]. France's recall rate increased by $17 \%$. When the aiming time is 50 , the recall rate of our method is $99 \%$, and the recall rate of the method proposed in reference [5] is 822 . The method in this paper is more effective than that in reference [5]. The recall rate is increased by $17 \%$, the recall rate of the method proposed in [7] is $89 \%$, the recall rate of this method is $10 \%$ higher than that of the method in [7]; when the aim time is 100 , the recall rate of the method in this paper is 100 , the recall rate of the proposed method in reference [5] is 933. The recall rate of the method in this paper is 7 percent higher than that of the method in reference [5], the recall rate of the method in reference [7] is 100, and the method in this paper and the method in [7] have been proposed. France has the same recall rate. Experimental data show that the proposed method is more accurate and effective in collecting hotspot data. 


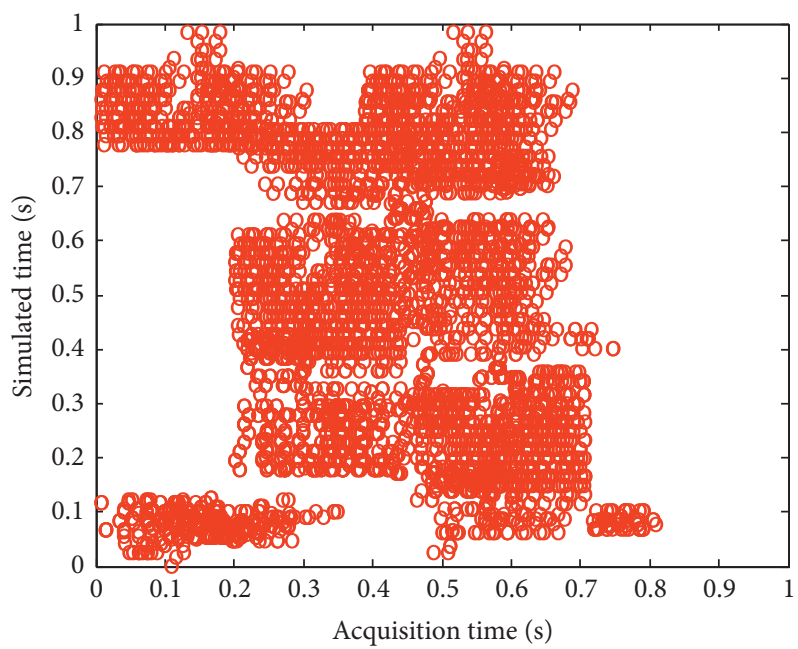

Figure 1: Big data hotspot collection results of English talents gathering.

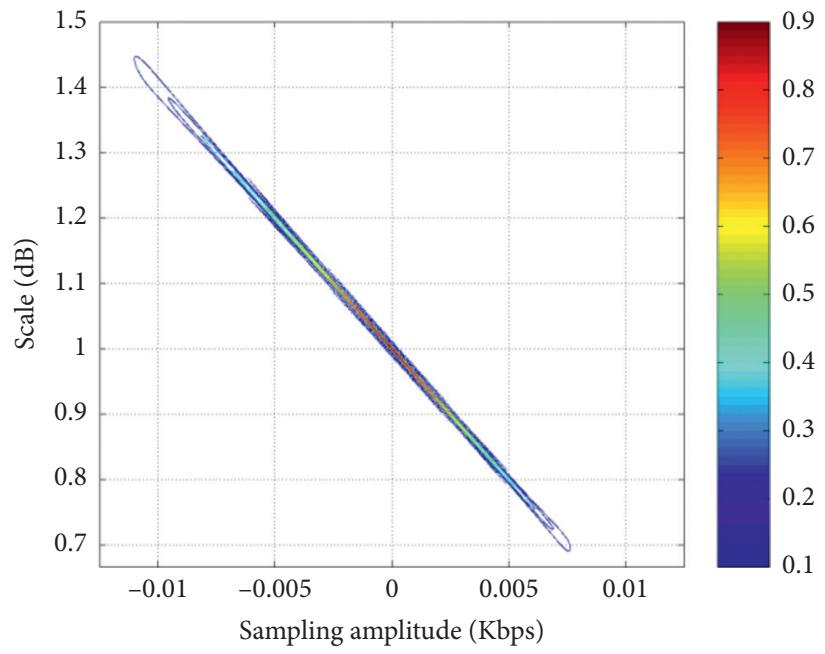

FIGURE 2: Feature extraction results.

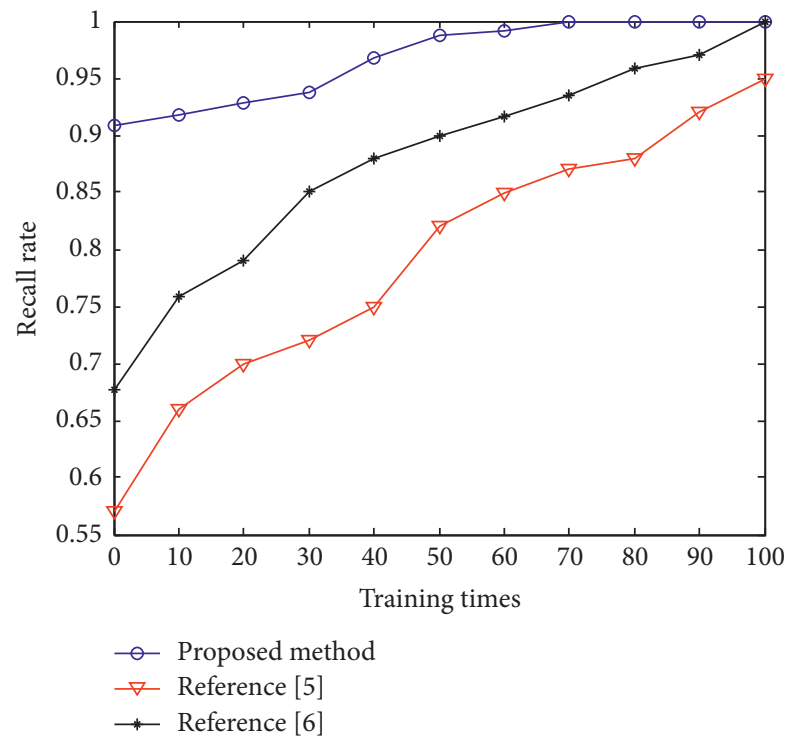

Figure 3: Accuracy comparison of big data hotspot collection with English talents gathering. 


\section{Conclusions}

In this paper, an English talents aggregation effect analysis model is proposed based on large-scale data collection technology. The piecewise linear test method is used to analyze the statistical characteristics of the hotspot big data of English talents aggregation effect and extract the frequent vector set which reflects the hot big data category attribute of English talents aggregation effect. According to the experimental result of feature extraction, the fuzzy English talents aggregation is processed to realize the fusion of big data information of English talents aggregation effect hotspot. Combined with the method of quantitative regression analysis, the automatic classification of hotspot big data association rules of English talents aggregation effect is realized. The experimental and simulation results of the study show that this approach has better accuracy and improved data aggregation effect in the collection of hotspot data of English talents gathering, and the ability of collecting and feature extraction of hotspot big data of English talents aggregation effect is improved. It has good application value in analysis of English talents gathering.

\section{Data Availability}

The data used to support the findings of this study are available from the corresponding author upon request.

\section{Conflicts of Interest}

The author declares that there are no conflicts of interest.

\section{Acknowledgments}

The study was supported by 2020 First-Class Undergraduate Course Construction Project of Xuchang University (no. PX-1620989) and 2017 Higher Education Reform Research and Practice Project in Henan Province (no. 2017SJGLX441).

\section{References}

[1] C. H. Ju and J. B. Zou, "An incremental classification algorithm for data stream based on information entropy diversity measure," Telecommunications Science, vol. 31, no. 2, pp. 86-96, 2015.

[2] Y. X. Lyu, C. Y. Wang, C. Wang et al., "Online classification algorithm for uncertain data stream in big data," Journal of Northeastern University (Natural Science Edition), vol. 37, no. 9, pp. 1245-1249, 2016.

[3] Y. Chen and L. J. Li, "Very fast decision tree classification algorithm based on red-black tree for data stream with continuous attributes," Journal of Nanjing University of Posts and Telecommunications (Natural Science Edition), vol. 37, no. 2, pp. 86-90, 2017.

[4] Y. Wu, B. Shen, and H. Ling, "Visual tracking via online nonnegative matrix factorization," IEEE Transactions on Circuits and Systems for Video Technology, vol. 24, no. 3, pp. 374-383, 2014.

[5] M. Ye, Y. Qian, and J. Zhou, "Multitask sparse nonnegative matrix factorization for joint spectral-spatial hyperspectral imagery denoising," IEEE Transactions on Geoscience and Remote Sensing, vol. 53, no. 5, pp. 2621-2639, 2015.

[6] L. R. Hu, J. G. Wu, and L. Wang, "Application and method for linear projective non-negative matrix factorization," Computer Science, vol. 40, no. 10, pp. 269-273, 2013.

[7] Y. Komai, D. H. Nguyen, T. Hara et al., "KNN search utilizing index of the minimum road travel time in time-dependent road networks," in Proceedings of the 2014 IEEE 33rd International Symposium on Reliable Distributed Systems Workshops, pp. 131-137, IEEE, Piscataway, NJ, USA, 2014.

[8] S. Ke, J. Gong, S. Li, Q. Zhu, X. Liu, and Y. Zhang, "A hybrid spatio-temporal data indexing method for trajectory databases," Sensors, vol. 14, no. 7, pp. 12990-13005, 2014.

[9] S. Ma, H. Wu, L. I. U. Zheng et al., "Method for emitter TDOA sorting based on recursive extended histogram," Journal of National University of Defense Technology, vol. 34, no. 5, pp. 83-89, 2012.

[10] J. Lin, "Brute force and indexed approaches to pairwise document similarity comparisons with mapreduce," in Proceedings of the 32nd International ACM SIGIR Conference on Research and Development in Information Retrieval, pp. 155-162, ACM, Boston, MA, USA, July 2009.

[11] R. Vernica, M. J. Carey, and C. Li, "Efficient parallel setsimilarity joins using mapreduce," in Proceedings of the 2010 ACM SIGMOD International Conference on Management of Data, pp. 495-506, ACM, Indianapolis, IN, USA, 2010.

[12] C. Rong, W. Lu, X. Wang, X. Du, Y. Chen, and A. K. H. Tung, "Efficient and scalable processing of string similarity join," IEEE Transactions on Knowledge and Data Engineering, vol. 25, no. 10, pp. 2217-2230, 2013.

[13] D. Miorandi, S. Sicari, F. De Pellegrini, and I. Chlamtac, "Internet of things: vision, applications and research challenges," Ad Hoc Networks, vol. 10, no. 7, pp. 1497-1516, 2012.

[14] S. K. Chong, M. M. Gaber, S. Krishnaswamy, and S. W. Loke, "Energy conservation in wireless sensor networks: a rulebased approach," Knowledge and Information Systems, vol. 28, no. 3, pp. 579-614, 2011.

[15] L. M. Oliveira and J. J. Rodrigues, "Wireless sensor networks: a survey on environmental monitoring," Journal of Communications, vol. 6, no. 2, pp. 143-151, 2011. 